Review Article

\title{
The Association of New-Onset Atrial Fibrillation and Risk of Cancer: A Systematic Review and Meta-Analysis
}

\author{
Mengxia Zhang (D), Lin-ling Li, Qian-qian Zhao, Xiao-dong Peng, Kui Wu, Xin Li, \\ Yan-Fei Ruan, Rong Bai, Nian Liu $\mathbb{D}$, and Chang Sheng Ma \\ Department of Cardiology, Beijing Anzhen Hospital, Capital Medical University, \\ National Clinical Research Center for Cardiovascular Diseases, No. 2 Anzhen Road, Chaoyang District, Beijing 100029, China
}

Correspondence should be addressed to Nian Liu; liunian1973@hotmail.com

Received 19 May 2020; Accepted 3 August 2020; Published 27 September 2020

Academic Editor: Francesco Fedele

Copyright (c) 2020 Mengxia Zhang et al. This is an open access article distributed under the Creative Commons Attribution License, which permits unrestricted use, distribution, and reproduction in any medium, provided the original work is properly cited.

\begin{abstract}
Background. There are distinct results for the relationship between new-onset atrial fibrillation (NOAF) and subsequent incident cancer. To date, no systematic analysis has been conducted on this issue. This study aims to explore the relationship between NOAF and the risk of developing cancer through a meta-analysis with a large sample size. Methods. Electronic databases, such as PubMed and EMBASE, were searched for published relevant studies on NOAF patients diagnosed with cancer after and during follow-ups, including reported records of baseline information and the statistical result of morbidity. Two investigators independently reviewed the articles and extracted the data using uniform standards and definitions. The meta-analysis was conducted using the Cochrane Program Review Manager. Results. This meta-analysis consisted of five cohort studies and one case-control study, which comprised 533,514 participants. The pooled relative risk (RR) for incident cancer was 1.24 (95\% CI: 1.10-1.39, $P=0.0003)$. The temporal trend analysis demonstrated that an increased risk of cancer was observed during the initial 90 days (RR: 3.44, 95\% CI: 2.29-5.57, $P<0.00001$ ), but not after that. Lung cancer (RR: 1.51, 95\% CI: $1.47-1.55, P<0.00001$ ) was associated with NOAF, but not colorectal cancer and breast cancer. Conclusion. This meta-analysis provides evidence that NOAF is associated with increased risk of cancer. The risk of incident cancer particularly increases within 90 days after NOAF diagnosis, but not after that.
\end{abstract}

\section{Introduction}

It has been well recognized that the new diagnosis of cancer would promote the subsequent development of new-onset atrial fibrillation (NOAF) [1]. The underlying mechanisms may be correlated with co-risk factors underlying the two independent disease entities and the medical interventions for cancer, such as chemotherapy and radiotherapy, which cause cardiotoxicity and predispose these patients to atrial fibrillation (AF).

Recently, several studies have demonstrated that NOAF may increase the risk of incident cancer, thereby shedding light on the mutual interactions between $\mathrm{AF}$ and cancer [2-4]. However, not all studies are in agreement with this association. AF is the most common type of sustained tachyarrhythmia encountered in clinical practice. Comorbid cancers in patients with NOAF significantly result in the complexity of clinical management and contribute to poor clinical outcomes [5]. Some AF trials have demonstrated that malignancy is the leading cause of death among noncardiovascular deaths $[6,7]$. The exploration of the link between NOAF and subsequent cancer is critical for the establishment of risk stratification and early intervention for patients with NOAF. The objective of the present metaanalysis was to determine whether NOAF increases the risk of development of cancer.

\section{Methods}

2.1. Search Strategy. According to the recommendations of the Meta-analysis of Observational Studies in Epidemiology Group [8], relevant English language articles were searched 
from electronic databases (PubMed, EMBASE, and Cochrane Library) updated to April 2020. All related MeSH headings and text search strategies were used with the following keywords: atrial fibrillation (AF), cancer (tumor and malignancy), morbidity (mortality), and relative risk (RR) or odds ratio (OR) or hazard ratio (HR). One particular instance is presented in Figure 1. The reference list of the published articles was manually checked to identify any additional studies.

2.2. Selection Criteria. The present study aimed to determine whether NOAF patients have a higher risk of developing cancer. Studies related to patients who have AF or cancer history were excluded. Studies that enrolled subjects based on patients with a specific disease condition or with unadjusted risks for associated events were further abnegated. If multiple studies were derived from the same cohort and covered by similar events, only the most complete studies and latest published information were incorporated for the present primary analysis. All ideal evidence should meet the following criteria: (1) observational studies with appropriate follow-up; (2) studies that shared the standard definition of AF and cancer patterns; (3) the included subjects were healthy, and the baseline raw data were generally comprehensive; (4) necessary information, such as the incident cancer reports of adjusted results and risk ratio (RR), odds ratio (OR), and hazard ratio (HR), was clearly expressed. Studies were excluded based on the following: (1) the articles were case reports, reviews, or basic research studies; (2) the data of the study were incomplete or duplicated.

2.3. Quality Assessment. Screening, data extraction, and critical appraisal were independently undertaken by two reviewers. In order to rule out irrelevant or repeating articles, the investigators perused the content of the remaining studies and assessed the quality of each report. Any possible divergence or indetermination was settled by discussion or arbitration with a third referee. For each eligible study, the Newcastle-Ottawa Quality Assessment Scale (NOS) was used to evaluate the quality and obtain the final scores. With a total rating of nine stars, a study that scores higher than or equal to seven stars was defined as high-quality research. Otherwise, the study was defined as low-quality research.

2.4. Data Extraction. The raw data were extracted, which included the following: (1) the necessary information of the qualified literature, such as the first author's name, publication time, region difference, and type of research; (2) the key elements to evaluate the risk of inclusion bias, such as disease definition, subgroup criteria, and the final score of NOS; (3) the medical details of subjects, with or without AF, and before or after the occurrence of cancer; (4) the significant outcome indicators at the end of the study. Furthermore, the RRs, HRs, ORs, and 95\% confidence intervals (CIs) that were preferentially multivariate adjusted, rather than age/gender adjusted, from separate articles were extracted to assess the relevance between AF and cancer.

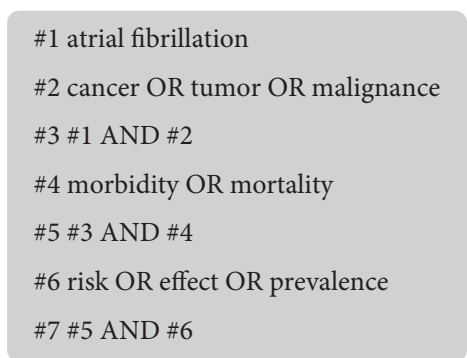

Figure 1: An example of the PubMed retrieval strategy.

2.5. Data Synthesis and Statistical Analysis. The data used for the present meta-analysis were based on the adjusted outcome from every included study and were logarithmically transformed. In addition, the corresponding standard errors (SE) were calculated and combined with the log relative risk using the inverse variance approach. The original HR/OR value in articles from the multivariate Cox proportional hazards model was regarded as the approximate RR. The $I^{2}$ test and $Q$ statistics were used to quantitatively determine the heterogeneity. If there was no statistical heterogeneity among the results (i.e., $P_{\mathrm{Q}}$ statistic $>0.1$ and $I^{2} \leq 50 \%$ ), the fixed-effect model can be adopted for the meta-analysis. Otherwise, the random-effect model was applied. This was due to the clinical and methodological differences between studies. Subgroup analyses for the main indicators, such as gender and the subtype of cancer, as well as the time interval between NOAF diagnosis and cancer, were conducted to search for heterogeneity sources. When the heterogeneity was high, the subgroup analysis had no significant effect on the final results. Hence, a sensitivity analysis was performed by omitting one study at a time, in order to examine the impact of each research on the estimated relative risk. The possible publication biases were identified by constructing funnel plots, in which the natural log relative risk was plotted against the SE. The meta-analysis was conducted using Cochrane Program Review Manager 5.3.

\section{Results}

3.1. Search Results. The flow diagram for the search and selection is presented in Figure 2. Initially, a total of 1,570 records were identified using the aforementioned strategies from the PubMed, EMBASE, and Cochrane Library. Then, 110 duplicate studies were excluded. The remaining 1,460 records were qualified for further screening by title or abstract. Finally, a total of 31 potentially eligible articles were scrutinized throughout the text. Merely six articles were eventually included for the present meta-analysis.

3.2. Quality Assessment and Study Characteristics. Five cohort studies and one case-controlled study were included with a satisfactory NOS score. The features are presented in Table 1 . The total number of participants was 533,514, and the average follow-up duration ranged within 3-19 years. Two studies only had female patients, while the other four studies had an approximately equal male/female ratio. The definition of AF and cancer was consistent in these studies. 


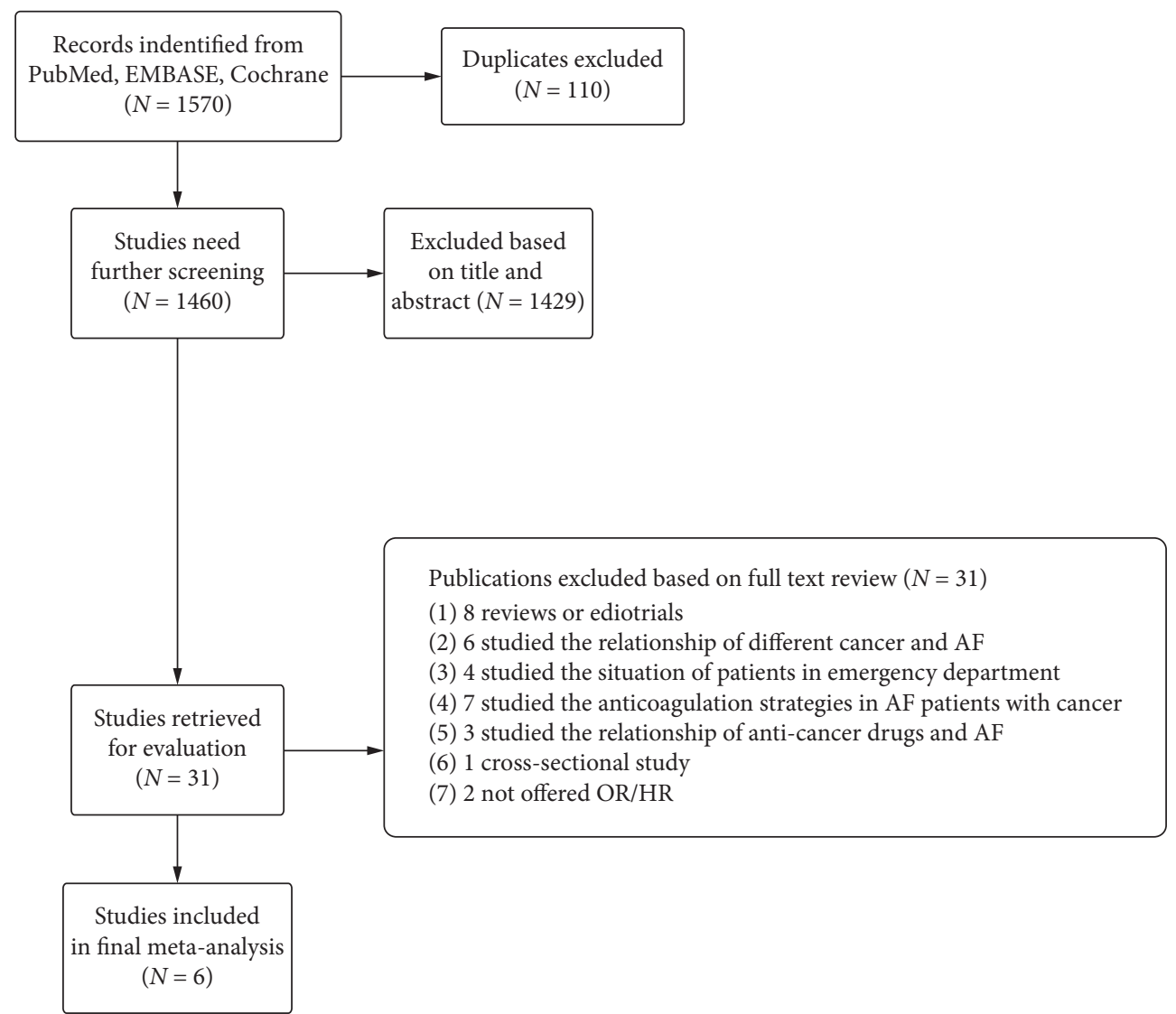

FIgURE 2: The flow diagram of the study selection process. AF, atrial fibrillation; OR, odds ratio; HR, hazard ratio.

Table 2 presents the characteristics of the patients involved in each article.

3.3. Meta-Analysis and Subgroup Analyses. The combined result from six separate studies revealed a link between NOAF and subsequent cancer. The summary RR was 1.24 (95\% CI: $1.10-1.39, P=0.0003, I^{2}=90 \%$; Figure 3), indicating that patients with NOAF have an approximately $24 \%$ higher risk of cancer, when compared with non-AF patients.

Next, an analysis of the temporal trend of cancer development was performed. The RR for cancer during the initial 90 days was the highest (RR: 3.44, 95\% CI: 2.29-5.57, $\left.P=0.00001, I^{2}=88 \%\right)$. However, the risk declined between 90 days and one year (RR: 1.38, 95\% CI: 0.90-2.12, $P=0.14$, $I^{2}=97 \%$ ) and beyond one year (RR: 1.09, 95\% CI: 0.95-1.24, $\left.P=0.24, I^{2}=92 \%\right)$. Another subgroup analysis was conducted to assess the risk of three common types of cancer events, respectively. Lung cancer (RR: 1.51, 95\% CI: $\left.1.47-1.55, P<0.00001, I^{2}=0 \%\right)$ was associated with NOAF, but not colorectal cancer (RR: 1.22, 95\% CI: 0.92-1.60, $\left.P=0.16, I^{2}=92 \%\right)$ or breast cancer (RR: $1.10,95 \% \mathrm{CI}$ : $\left.0.94-1.29, P=0.25, I^{2}=80 \%\right)$. The subgroup analysis on gender revealed that both male NOAF patients (RR: 1.39, 95\% CI: $\left.1.33-1.45, P<0.00001, I^{2}=21 \%\right)$ and female NOAF patients (RR: $1.26,95 \%$ CI: $1.11-1.44, P=0.00005, I^{2}=78 \%$ ) have a higher risk of developing cancer, when compared with non-AF patients with the same gender (Table 3).
3.4. Sensitivity Analysis. The funnel plot (Figure 4) presents the limited symmetry distribution of all the research studies, with only one research randomly beyond 95\% CI, which need to be examined. That is, the study conducted by Saliba et al. [12] was the only case-control report and was influenced by potential selection bias. The integrated result was optimized (RR: $1.35,95 \%$ CI: $1.28-1.42, \quad P<0.00001$, $\left.I^{2}=46 \%\right)$ after discarding the study conducted by Saliba et al. [12].

\section{Discussion}

Six published observational articles were incorporated into the present analysis [9-14]. The integrated result demonstrated that patients with NOAF have a $24 \%$ increased risk of developing cancer. The subgroup analysis stratified by time interval, gender, and type of cancer revealed the following: (1) the incident cancer significantly increased within 90 days after NOAF diagnosis, but not after that; (2) males appeared to have a higher risk, when compared with females; (3) the risk of lung cancer, but not colorectal cancer or breast cancer, was higher in patients with NOAF, when compared with non-AF patients.

$\mathrm{AF}$ is associated with increased cardiovascular morbidity and mortality, while patients with AF are exposed to a substantial risk of death due to noncardiovascular causes. The initial case-control study conducted by Muller et al. [15] reported that $\mathrm{AF}$ is associated with an increased occurrence 
TABLE 1: The characteristics of studies included in the meta-analysis.

\begin{tabular}{|c|c|c|c|c|c|c|c|c|c|}
\hline Study & Design & Location & Participants & Total, N & Excluded & $\begin{array}{l}\text { Period of } \\
\text { enrollment }\end{array}$ & $\begin{array}{l}\text { Follow-up } \\
\text { duration } \\
\text { (median) }\end{array}$ & $\begin{array}{c}\text { Covariates in } \\
\text { an adjusted } \\
\text { model }\end{array}$ & $\begin{array}{l}\text { NOS } \\
\text { score }\end{array}$ \\
\hline $\begin{array}{l}\text { Conen } 2016 \\
\text { [9] }\end{array}$ & $\begin{array}{l}\text { Prospective } \\
\text { cohort study }\end{array}$ & USA & $\begin{array}{l}\text { Female health } \\
\text { professionals } \\
\qquad(>45)\end{array}$ & 34691 & $\begin{array}{c}\text { Prior } \\
\mathrm{AF} / \mathrm{CA} / \mathrm{CVD}\end{array}$ & 1993-2013 & $\begin{array}{c}19.1 \\
(17.6-19.7)\end{array}$ & $\begin{array}{c}\text { Age, BMI, } \\
\text { HTN, DM, } \\
\text { smoke, race, } \\
\text { and } \\
\text { comorbidity }\end{array}$ & 9 \\
\hline $\begin{array}{l}\text { Wassertheil } \\
2017[10]\end{array}$ & $\begin{array}{l}\text { Prospective } \\
\text { cohort study }\end{array}$ & USA & $\begin{array}{l}\text { Postmenopausal } \\
\text { women }(50-79)\end{array}$ & 86046 & NA & From 1994 & 15.9 & $\begin{array}{c}\text { Age, race, } \\
\text { parity, age at } \\
\text { first birth, and } \\
\text { cancer-specific } \\
\text { potential } \\
\text { confounders }\end{array}$ & 8 \\
\hline $\begin{array}{l}\text { Hung } 2018 \\
{[11]}\end{array}$ & $\begin{array}{l}\text { Retrospective } \\
\text { cohort study }\end{array}$ & $\begin{array}{l}\text { Taipei, } \\
\text { China }\end{array}$ & $\begin{array}{c}\text { Individual from } \\
2005\end{array}$ & 5130 & $\begin{array}{c}<20 \text { Y Prior } \\
\text { AF/CA }\end{array}$ & 2005-2010 & $3.4 \pm 2$ & NA & 8 \\
\hline $\begin{array}{l}\text { Saliba } 2018 \\
\text { [12] }\end{array}$ & $\begin{array}{l}\text { Prospective } \\
\text { case-control } \\
\text { studies }\end{array}$ & $\begin{array}{l}\text { USA and } \\
\text { Israel }\end{array}$ & NA & 19991 & NA & From 1998 & $>3 Y$ & $\begin{array}{l}\text { Age, sex, } \\
\text { smoking, } \\
\text { alcohol } \\
\text { consumption, } \\
\text { education, } \\
\text { medication } \\
\text { use, and } \\
\text { comorbidity }\end{array}$ & 8 \\
\hline $\begin{array}{l}\text { Vinter } 2018 \\
{[13]}\end{array}$ & $\begin{array}{l}\text { Prospective } \\
\text { cohort study }\end{array}$ & Denmark & NA & 55101 & $\begin{array}{l}\text { Nonmelanoma } \\
\text { skin cancer }\end{array}$ & 1993-2013 & 19.7 & $\begin{array}{c}\text { Age, BMI, } \\
\text { smoking } \\
\text { duration, and } \\
\text { alcohol } \\
\text { consumption, }\end{array}$ & 7 \\
\hline $\begin{array}{l}\text { Hung } 2019 \\
{[14]}\end{array}$ & $\begin{array}{l}\text { Prospective } \\
\text { cohort study }\end{array}$ & $\begin{array}{l}\text { Taipei, } \\
\text { China }\end{array}$ & $\mathrm{NA}$ & 332555 & $<20$ Y Prior CA & 1996-2011 & $\begin{array}{c}3.1 \\
(0.97-6.53)\end{array}$ & $\begin{array}{l}\text { Age, sex, risk } \\
\text { factors, and } \\
\text { comorbidity }\end{array}$ & 8 \\
\hline
\end{tabular}

AF, atrial fibrillation; CA, cancer; CVD, cardiovascular disease; BMI, body mass index; HTN, hypertension; DM, diabetes mellitus; NA, not applicable; NOS, Newcastle-Ottawa Quality Assessment Scale.

of colon cancer after 5-10 years, prompting a series of studies to explore the relationship between NOAF and subsequent cancer development. However, distinct results were observed. These discrepancies may be attributable to the sample scale or selection bias in the study population. In order to systematically and comprehensively evaluate the relationship between those two entities, the present metaanalysis on NOAF and risk of cancer development was conducted for the first time.

Classic cardio-oncology focuses on the detection, monitoring, and treatment of the cardiovascular complications of chemotherapy and radiotherapy in patients with cancer. More recently, an emerging field called reverse cardio-oncology has increasingly gained the attention for patients with cardiovascular diseases who develop cancer, which significantly expands the concept of cardio-oncology [16]. The shared risk factors, oxidative stress, and inflammation signaling pathway may underlie the mutual action between cardiovascular disease and cancer [17-19]. For example, cohort studies, a meta-analysis, and a mice model study demonstrated that heart failure increased the risk of cancer development. AF and cancer share co-risk factors, such as old age, tobacco, alcoholism, obesity, diabetes mellitus, and so on [20-23]. Hung et al. [14] reported that aging, male gender, hypertension, diabetes, chronic obstructive pulmonary disease (COPD), and liver cirrhosis were significantly associated with the development of cancer among patients with AF. More intriguingly, the authors reported that there was a positive correlation between the number of risk factors and risk of cancer. The HR for cancer was 1.4 in patients with one risk factor, and this increased to 5.14 in patients with six risk factors. Furthermore, the negative effects of anxiety disorder cannot be ignored [24]. Long-term anxiety due to psychological factors or chronic diseases, such as AF, overactivates the hypothalamic-pituitary-adrenal (HPA) axis and the sympathetic-adrenalmedullary axis, elevating corticosterone and other stress hormones [25]. These hormones are not only associated with low-level systemic inflammation, leading to ultrastructural atrial remodeling [24], but also may impair immune and endocrine functions and participate in the regulation of tumor microenvironmental activity [26, 27]. In this scenario, it is applauding that AF may be a risk factor for cancer.

All six studies presented the high risk of cancer development in the first 90 days after NOAF diagnosis, while different results were observed beyond 90 days. One study 


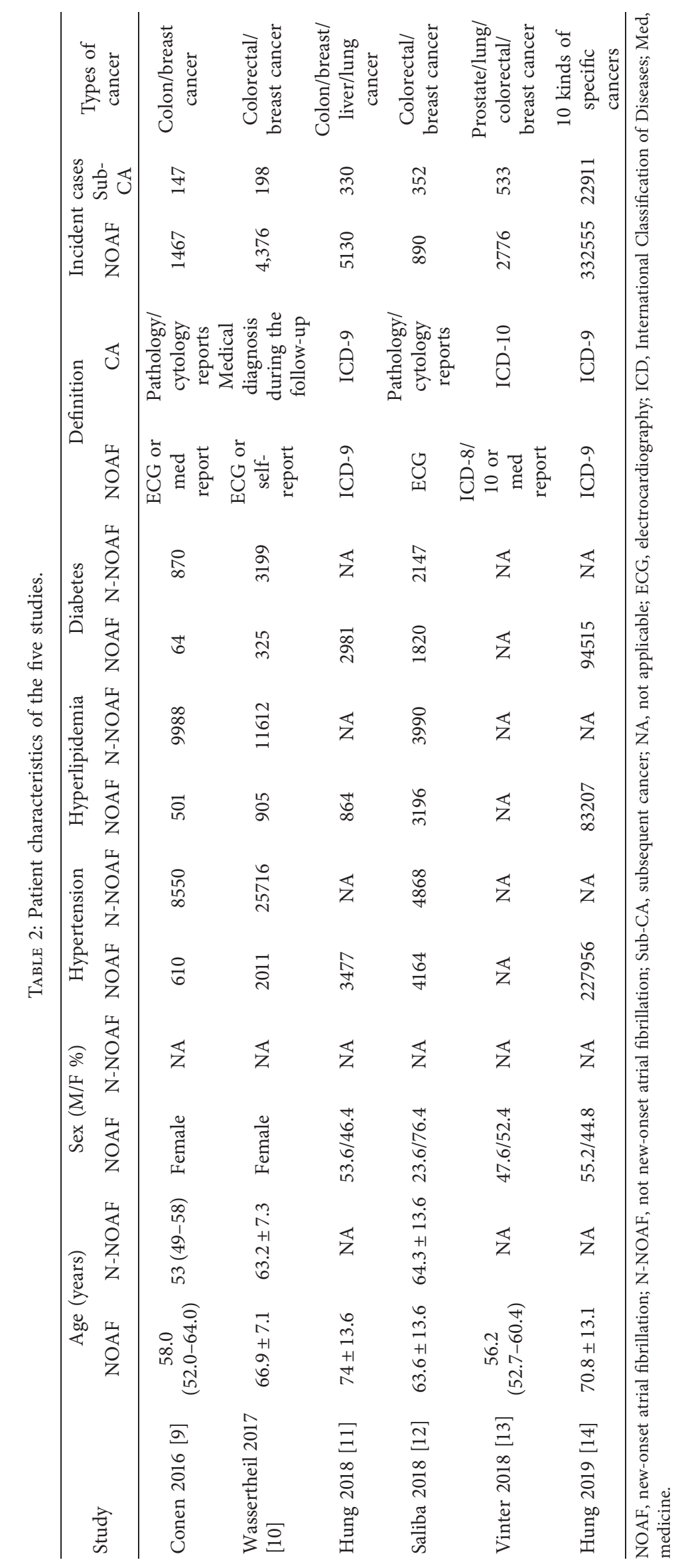




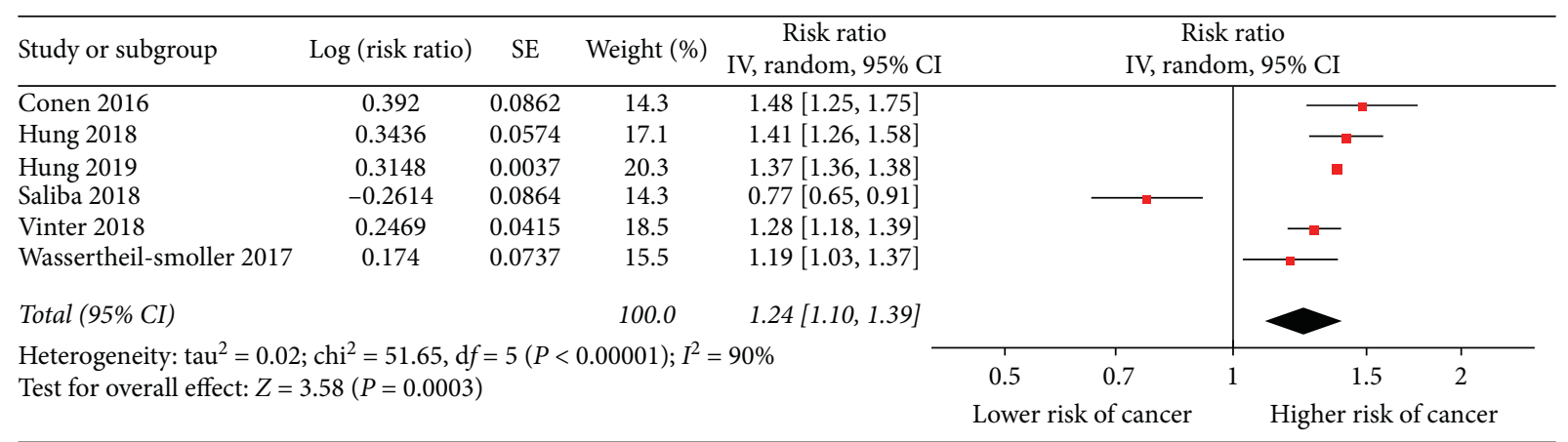

FIgURE 3: The forest plot for the combined effect quantities of the risk of cancer in AF patients. SE, standard error; IV, inverse variance.

TABle 3: The subgroup analysis of the association between AF and CA..

\begin{tabular}{|c|c|c|c|c|c|c|c|}
\hline \multirow{2}{*}{ Study } & \multirow{2}{*}{ Subgroup } & \multirow{2}{*}{ Number of studies } & \multirow{2}{*}{$\mathrm{RR}$} & \multicolumn{2}{|c|}{ Meta-analysis } & \multirow{2}{*}{ Heterogeneity $I^{2}(\%)$} & \multirow{2}{*}{$\begin{array}{l}\text { Test for subgroup } \\
\text { differences } I^{2}(\%)\end{array}$} \\
\hline & & & & $95 \% \mathrm{CI}$ & $P$ value & & \\
\hline \multirow[b]{2}{*}{ Gender } & Male & 3 & 1.39 & $\begin{array}{l}1.33 \\
1.45\end{array}$ & $<0.00001$ & 21 & \multirow[b]{2}{*}{44.7} \\
\hline & Female & 3 & 1.26 & $\begin{array}{l}1.4 J \\
1.11 \\
1.44\end{array}$ & 0.0005 & 78 & \\
\hline \multirow{3}{*}{ Subtype of cancer } & $\begin{array}{l}\text { Colorectal } \\
\text { cancer }\end{array}$ & 6 & 1.22 & $\begin{array}{l}0.92 \\
1.60\end{array}$ & 0.16 & 92 & \multirow{3}{*}{87.9} \\
\hline & Lung cancer & 4 & 1.51 & $\begin{array}{l}1.47 \\
1.55\end{array}$ & $<0.00001$ & 0 & \\
\hline & Breast cancer & 5 & 1.10 & $\begin{array}{l}0.94 \\
1.29 \\
\end{array}$ & 0.25 & 80 & \\
\hline \multirow{3}{*}{$\begin{array}{l}\text { Time interval between CA } \\
\text { diagnosis and AF }\end{array}$} & $<3 \mathrm{M}$ & 4 & 3.44 & $\begin{array}{l}2.29 \\
5.17\end{array}$ & $<0.00001$ & 88 & \multirow{3}{*}{92.9} \\
\hline & $3-12 \mathrm{M}$ & 4 & 1.38 & $\begin{array}{l}0.90 \\
2.12\end{array}$ & 0.14 & 97 & \\
\hline & $>12 \mathrm{M}$ & 4 & 1.09 & $\begin{array}{l}0.95 \\
1.24\end{array}$ & 0.24 & 92 & \\
\hline
\end{tabular}

$\mathrm{AF}$, atrial fibrillation; $\mathrm{CA}$, cancer; $\mathrm{RR}$, risk ratio.

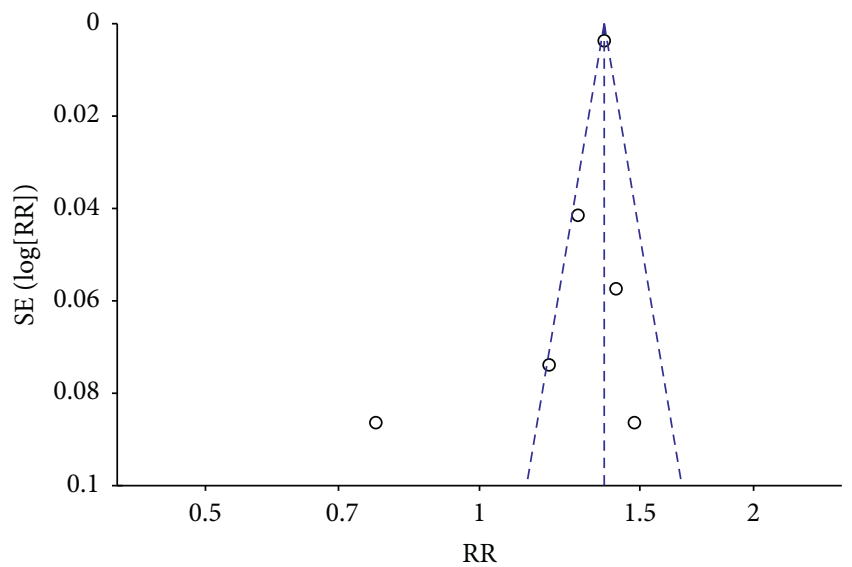

Figure 4: The funnel plot for all studies. SE, standard error; RR, risk ratio.

revealed that an AF duration longer than 90 days is associated with reduced risk of cancer. The present meta-analysis revealed that patients with NOAF have a $24 \%$ higher risk of developing cancer. The temporal trends in the subgroup analysis demonstrated that the increased risk of cancer could be observed in the initial 90 days, while the risk declined after that. Thus, the present data did not lend support for the causal relationship between these two entities since there was no accumulative or successive impact on the cancer development in the long-term follow-up of patients with NOAF. There are several interpretations for these data. (1) $\mathrm{AF}$ and cancer share co-risk factors, and occult cancer might already exist before patients were diagnosed with AF. Frequent visits to the medical system for AF would increase the chance of early detection of cancer. Vinter et al. [13] reported that NOAF is closely associated with metastatic cancer within 90 days in the same year, further supporting the concept that patients with NOAF may be accompanied by occult cancers. (2) Atrial natriuretic peptide (ANP) related to $\mathrm{AF}$ has been shown to have extensive antiproliferative effects and might account for the significant reduction in cancer incidence after 90 days. (3) Anticoagulant therapy is the cornerstone of treatment for AF. Warfarin inhibits tyrosine kinase-dependent oncogenesis and enhances antitumor immune responses. A populationbased cohort study revealed that warfarin lowers cancer incidence [28]. Thus, warfarin could counteract the oncogenesis induced by AF. 
Another subgroup analysis was conducted to assess the association between cancer subtypes and AF. It was found that lung cancer is associated with NOAF but not colorectal cancer or breast cancer. A Danish cohort study [14] demonstrated that an increased risk of lung cancers and AF was found in subjects with high-risk behaviors, such as smoking, which are the common factors related to the development of $\mathrm{AF}$, as well as lung cancer. Although radiation exposure to a patient with NOAF, such as chest X-ray or computed tomography, may trigger the malignant condition in the lungs, it is unlikely that X-ray exposure in routine clinical practice increases the risk of lung cancer within 90 days. It has been well recognized that patients with AF are prone to bleeding after anticoagulant drug therapy, especially gastrointestinal (GI) bleeding. GI bleeding is also correlated with potential pathological lesions, including inflammatory or diverticular disease, ulcers, vascular malformations, radiation enteropathy, and malignancies [29]. The study conducted by Clemens et al. [30] revealed that, for AF patients with dabigatran, the incidence of nongastrointestinal tumors was only $0.05 \%$, while the incidence of gastrointestinal tumors was $0.5 \%$. Thus, GI bleeding would advance the screening and intervention, resulting in the early diagnosis of colorectal cancer. Breast cancer is one of the most common malignant tumors in female patients. The regular administration of antiarrhythmic drugs may increase the risk of breast cancer in women with AF [10]. Studies have shown that digoxin has estrogen-like effects and significantly increases the risk of breast cancer in female AF patients $[31,32]$. However, the present meta-analysis did not confirm the association between NOAF and colorectal cancer or breast cancer. Notably, the high heterogeneities were in the two subgroup analysis, in which the reliability of the association between NOAF and colorectal cancer remains to be verified.

There was a gender difference found in the present study. Male patients with NOAF had a $39 \%$ increased risk of developing cancer, whereas female patients had a $26 \%$ greater risk. In general, female patients with NOAF are associated with poor clinical outcomes. Two studies included in the present meta-analysis enrolled only women patients, which caused selective gender bias. Therefore, these results may not apply to the whole population.

These present findings may have relevance in the management of patients with NOAF. A notable increase in incident cancer within 90 days after NOAF diagnosis highlights that an appropriate strategy should be considered to screen for cancer for these patients, especially for the patients with a higher burden of risk factors, such as aging and smoking. To date, it remains unclear whether earlier diagnosis would improve the management of patients with NOAF.

\section{Study Limitation}

The present meta-analysis has several potential limitations that call for caution when interpreting the results. First, a small number of studies were included for the meta-analysis, and there was high heterogeneity among these studies. The study conducted by Saliba et al. [12] was a case-control study, which was prone to representative crowd bias. Second, eligible studies in the English language were included, while studies in non-English languages were missed. This would cause potential publication bias due to the limited number of studies. Third, NOAF and cancer share co-risk factors, which the investigators propose as the underlying mechanism for the association between NOAF and the subsequent cancer diagnosis. Risk factors, such as smoking, age, and alcohol consumption, are critical for the further analysis. Unfortunately, this information was not available.

\section{Conclusion}

The present systematic review and meta-analysis indicated that NOAF may increase the incidence of cancer. The risk of incident cancer was particularly elevated within 90 days after NOAF diagnosis, but not after that period.

\section{Data Availability}

The data underlying this study are available within the article and in Supplementary Materials.

\section{Conflicts of Interest}

The authors declare that they have no conflicts of interest.

\section{Acknowledgments}

This work was supported in part by grants from the National Natural Science Foundation of China (nos. 81870244 and 81670291) and the Beijing Natural Science Foundation (no. 7192051).

\section{References}

[1] F. Rahman, G. F. Kwan, and E. J. Benjamin, "Global epidemiology of atrial fibrillation," Nature Reviews Cardiology, vol. 11, no. 11, pp. 639-654, 2014.

[2] E. B. Ostenfeld, R. Erichsen, L. Pedersen et al., "Atrial fibrillation as a marker of occult cancer," PLoS One, vol. 9, no. 8, Article ID e102861, 2014.

[3] G. Chu, H. H. Versteeg, A. J. Verschoor et al., "Atrial fibrillation and cancer-an unexplored field in cardiovascular oncology," Blood Reviews, vol. 35, pp. 59-67, 2019.

[4] D. Farmakis, J. Parissis, and G. Filippatos, "Insights into oncocardiology," Journal of the American College of Cardiology, vol. 63, no. 10, pp. 945-953, 2014.

[5] V. Allan, S. Honarbakhsh, J. P. Casas et al., “Are cardiovascular risk factors also associated with the incidence of atrial fibrillation? A systematic review and field synopsis of 23 factors in 32 population-based cohorts of 20 million participants," Thromb Haemost, vol. 117, no. 5, pp. 837-850, 2017.

[6] E. B. Pathak, "Is heart disease or cancer the leading cause of death in United States women?" Women's Health Issues: Official Publication of the Jacobs Institute of Women's Health, vol. 26, no. 6, pp. 589-594, 2016.

[7] S. T. Chen, A. S. Hellkamp, R. C. Becker et al., "Efficacy and safety of rivaroxaban vs. warfarin in patients with non-valvular atrial fibrillation and a history of cancer: observations 
from ROCKET AF," European Heart Journal-Quality of Care and Clinical Outcomes, vol. 5, no. 2, pp. 145-152, 2019.

[8] D. F. Stroup, J. A. Berlin, S. C. Morton et al., "Meta-analysis of observational studies in epidemiology," JAMA, vol. 283, no. 15, pp. 2008-2012, 2000.

[9] D. Conen, J. A. Wong, R. K. Sandhu et al., "Risk of malignant cancer among women with new-onset atrial fibrillation," JAMA Cardiology, vol. 1, no. 4, pp. 389-396, 2016.

[10] S. Wassertheil-Smoller, A. P. McGinn, L. Martin et al., "The associations of atrial fibrillation with the risks of incident invasive breast and colorectal cancer," American Journal of Epidemiology, vol. 185, no. 5, pp. 372-384, 2017.

[11] C.-S. Hung, C.-H. Chang, J.-W. Lin et al., "The association between new onset atrial fibrillation and incident cancer-A nationwide cohort study," PLoS One, vol. 13, no. 6, Article ID e0199901, 2018.

[12] W. Saliba, H. S. Rennert, N. Gronich et al., "Association of atrial fibrillation and cancer: analysis from two large population-based case-control studies," PloS One, vol. 13, no. 1, Article ID e0190324, 2018.

[13] N. Vinter, A. M. S. Christesen, M. Fenger-Grøn et al., "Atrial fibrillation and risk of cancer: a Danish population-based cohort study," Journal of the American Heart Association, vol. 7, no. 17, Article ID e009543, 2018.

[14] Y.-P. Hung, Y.-W. Hu, C.-J. Liu et al., "Risk and predictors of subsequent cancers of patients with newly-diagnosed atrial fibrillation - a nationwide population-based study," International Journal of Cardiology, vol. 296, pp. 81-86, 2019.

[15] A. D. Müller, A. Sonnenberg, and I. H. Wasserman, "Diseases preceding colon cancer. A case-control study among veterans," Digestive Diseases and Sciences, vol. 39, no. 11, pp. 2480-2484, 1994.

[16] J. P. Aboumsallem, J. Moslehi, and R. A. de Boer, "Reverse cardio-oncology: cancer development in patients with cardiovascular disease," Journal of the American Heart Association, vol. 9, no. 2, Article ID e013754, 2020.

[17] B. L. Tan, M. E. Norhaizan, W.-P.-P. Liew et al., “Antioxidant and oxidative stress: a mutual interplay in age-related diseases," Frontiers in Pharmacology, vol. 9, p. 1162, 2018.

[18] P. M. Ridker, "Inflammation, cardiovascular disease and cancer: moving toward predictive medicine," CMAJ: Canadian Medical Association journal = journal de l'Association medicale canadienne, vol. 189, no. 10, pp. E382-E383, 2017.

[19] L. Zuo, E. R. Prather, M. Stetskiv et al., "Inflammaging and oxidative stress in human diseases: from molecular mechanisms to novel treatments," International Journal of Molecular Sciences, vol. 20, no. 18, p. 4472, 2019.

[20] K. Rose-Felker, W. L. Border, B. J. Hong et al., "Cardiooncology related to heart failure: pediatric considerations for cardiac dysfunction," Heart Failure Clinics, vol. 13, no. 2, pp. 311-325, 2017.

[21] L. Frost, L. J. Hune, and P. Vestergaard, "Overweight and obesity as risk factors for atrial fibrillation or flutter: the Danish Diet, Cancer, and Health Study," The American Journal of Medicine, vol. 118, no. 5, pp. 489-495, 2005.

[22] C. D. Parry, J. Patra, and J. Rehm, "Alcohol consumption and non-communicable diseases: epidemiology and policy implications," Addiction (Abingdon, England), vol. 106, no. 10, pp. 1718-1724, 2011.

[23] F. Rahman, D. Ko, and E. J. Benjamin, "Association of atrial fibrillation and cancer," JAMA Cardiology, vol. 1, no. 4, pp. 384-386, 2016.
[24] P. Severino, M. V. Mariani, A. Maraone et al., "Triggers for atrial fibrillation: the role of anxiety," Cardiology Research and Practice, vol. 2019, Article ID 1208505, , 2019.

[25] C.-C. Shen, Y.-W. Hu, L.-Y. Hu et al., "The risk of cancer in patients with generalized anxiety disorder: a nationwide population-based study," PLoS One, vol. 8, no. 2, Article ID e57399, 2013.

[26] M. H. Antoni, S. K. Lutgendorf, S. W. Cole et al., "The influence of bio-behavioural factors on tumour biology: pathways and mechanisms," Nature Reviews Cancer, vol. 6, no. 3, pp. $240-248,2006$.

[27] E. V. Yang and R. Glaser, "Stress-induced immunomodulation: implications for tumorigenesis," Brain, Behavior, and Immunity, vol. 17, no. 1, pp. S37-S40, 2003.

[28] G. S. Haaland, R. S. Falk, O. Straume et al., "Association of warfarin use with lower overall cancer incidence among patients older than 50 years," JAMA Internal Medicine, vol. 177, no. 12, pp. 1774-1780, 2017.

[29] K. Oakland, G. Chadwick, J. E. East et al., "Diagnosis and management of acute lower gastrointestinal bleeding: guidelines from the British Society of Gastroenterology," Gut, vol. 68 , no. 5, pp. 776-789, 2019.

[30] A. Clemens, A. Strack, H. Noack et al., "Anticoagulant-related gastrointestinal bleeding--could this facilitate early detection of benign or malignant gastrointestinal lesions?" Annals of Medicine, vol. 46, no. 8, pp. 672-678, 2014.

[31] T. P. Ahern, T. L. Lash, H. T. Sørensen et al., "Digoxin treatment is associated with an increased incidence of breast cancer: a population-based case-control study," Breast Cancer Research: BCR, vol. 10, no. 6, p. R102, 2008.

[32] T. P. Ahern, R. M. Tamimi, B. A. Rosner et al., "Digoxin use and risk of invasive breast cancer: evidence from the Nurses' Health Study and meta-analysis," Breast Cancer Research and Treatment, vol. 144, no. 2, pp. 427-435, 2014. 